\title{
Critical Analysis of Pharmaceuticals Inventory Management Using the ABC-VEN Matrix in Dessie Referral Hospital, Ethiopia
}

This article was published in the following Dove Press journal: Integrated Pharmacy Research and Practice

\section{Solomon Ahmed Mohammed iD Birhanu Demeke Workneh \\ Department of Pharmacy, College of Medicine and Health Science, Wollo University, Dessie, Ethiopia}

Introduction: Inventory management is a complex process that accelerates the probability of stock-out and overstocking if not tracked properly. Classification of drugs based on their criticality, cost burden, and in combination is important to make inventory decisions and optimize the quality use of scarce resources. This study analyzed the pharmaceutical inventory management systems of Dessie Referral Hospital using the ABC-VEN matrix for the years 2013 to 2017.

Methodology: Cross-sectional study design was used to review logistic data retrospectively from health commodity management information system and manual records. Data were collected from January 1-20, 2018 in Dessie Referral Hospital.

Results: In the five-year ABC-VEN analysis, 310 (17\%), 368 (20.18\%), and 1146 (62.83\%) items were class A, B, and C, while 610 (34.56\%), $1125(63.74 \%)$, and $30(1.7 \%)$ of pharmaceuticals were V, E, and N, respectively. Among these, 139 (7.88\%) and 339 (19.21\%) of $\mathrm{AV}$ and $\mathrm{CV}$ pharmaceuticals utilized $43.52 \%$ and $2.89 \%$ of annual drug expenditures, respectively. Category I, II, and III pharmaceuticals also accounted for $43.68 \%, 54.79 \%$, and $1.53 \%$ of items with their respective USD drug expenditure of $2,268,405.64$ (84.49\%), 411,961.18 (15.34\%), and $4483.97(0.17 \%)$. The pharmaceutical inventory cost projected to be $1,619,351.79$ USD in 2025 and total cost $(\beta=10.68, \mathrm{p}=$ $0.001)$, class $A(\beta=8.68, p=0.001)$, class $B(\beta=1.27, p=0.007)$, class $C(\beta=0.72, p=0.03)$, and $\mathrm{E}$ items $(\beta=6.08, p=0.01)$ were statistically significant with inventory cost.

Conclusion: A huge amount of budget is invested in class A and category I, which pinpoints the need for strict inventory control to prevent wastage and accumulation of capital in buffer stocks. ABC-VEN analysis should be routinely performed before initiation of any new procurement for efficient use of scarce resources.

Keywords: inventory management, $\mathrm{ABC}$ analysis, VEN analysis, $\mathrm{ABC}-\mathrm{VEN}$ matrix

\section{Introduction}

Inventory management is the core of the pharmaceutical supply system and is involved in ordering, receiving, storing, issuing, and reordering of products. ${ }^{1}$ Its objective is to make inventory decisions that minimize the total inventory cost and optimize quality through the use of scarce resources to meet the actual needs of consumers in an efficient manner. ${ }^{2}$

About one-third of the hospital budget is spent on purchasing various materials and supplies, including medicines, and forty per cent of budget spent on the procurement and management of stores. ${ }^{3}$ This urges effective and efficient inventory management to bring significant improvement in medical store management. ${ }^{4,5}$ 
Developing countries drug expenditure accounted $60-80 \%$ of their populations. ${ }^{6}$ But up to $90 \%$ of the population in developing countries purchase medicines through outof-pocket payments. ${ }^{7}$ A study in Tanzania explored that received near expiry date drugs were the main reason for stock out. ${ }^{8}$ Inventory control policies used for distributing medicines in sub-Saharan Africa directly account for a substantial fraction of stock-outs and resulted in demand seasonality and facility access interruptions. ${ }^{9,10}$

Hospital management has always been concerned with optimizing logistics costs in a healthcare supply chain. ${ }^{11,12}$ But pharmacy inventory management is a complex process and the usual problems encountered when inventory is not tracked properly and inefficiency is excessive losses, improper technology use, and lack of logistical infrastructure to store drugs, improper monitoring of drug expiration times, distribution problems, and irrational usage of drugs. ${ }^{13}$ This accelerates the probability of stock out and overstocking of essential drugs resulted in wastage or blockade of financial resources, increase in out-of-pocket expenditure, and ultimately decline in the quality of healthcare services. ${ }^{14,15}$

Continuous management has an affects the management of financial resources. ${ }^{16}$ The regular supply of adequate amounts of appropriate health commodities is crucial for health services to be effective and credible. Improving pharmacy inventory management enables health institutions to reconcile budget requirements', adhere to regulatory requirements, maintain sufficient stock of items, and reduce risks related to patient safety. ${ }^{17}$

The classification of pharmaceuticals based on their criticality (Vital, Essential, and Normal-VEN) or cost burden (Always, Better, and Control-ABC), is important for effective supply chain management and budgetary control, respectively. ${ }^{18}$ Vital medicines are potentially lifesaving and are crucial to providing basic health services. Essential medicines are effective against less severe, but significant forms of illness, but are not absolutely vital to providing basic health care. Normal medicines are used for minor or self-limited illnesses. ${ }^{19}$

$\mathrm{ABC}$ analysis helps in identifying items that require greater attention for control. In this, $10 \%$ items consumed about $70 \%$ of the budget (Group A). The next $20 \%$ inventory items take away $20 \%$ of the financial resources (Group B) and the remaining 70\% items account for just $10 \%$ of the budget (Group C). ${ }^{20}$

A combination of $\mathrm{ABC}$ and VEN analysis (ABC-VEN matrix) can be gainfully employed to develop meaningful control over the material supplies. Category I includes all $\mathrm{V}$ and $\mathrm{E}$ items (AV, BV, CV, AE, AN). Category II includes the remaining items of the $\mathrm{E}$ and $\mathrm{B}$ groups $(\mathrm{BE}, \mathrm{CE}, \mathrm{BN})$. Category III includes the desirable and cheaper group of items $(\mathrm{CN}){ }^{21}$

\section{Materials and Methods Study Area and Period}

A study was conducted from January 1 to June 30, 2018 of the Dessie Referral Hospital (DRH), Dessie, Ethiopia. Dessie is located in the South Wollo zone of Amhara Regional State, 401 kilometers away from Addis Ababa, the capital city of Ethiopia. Dessie referral hospital is a large institution serving Dessie town and the surrounding population, accounting for about 7 million.

\section{Study Design}

A cross-sectional study design was used to retrospectively review logistic data from the electronic health commodity management information system and manual records.

\section{Source Population}

All pharmaceuticals received in Dessie Referral Hospital between January 1, 2013 to December 31, 2017.

\section{Study Population}

All pharmaceuticals were purchased using a revolving drug fund in Dessie Referral Hospital between January 1, 2013 to December 31, 2017.

\section{Study Units}

The study subjects were all pharmaceuticals purchased using a revolving drug fund in Dessie Referral Hospital between January 1, 2013 to December 31, 2017. The sample was representative since all elements of the pharmaceutical had the same chance to be part of the sample.

\section{Inclusion and Exclusion Criteria}

The study considered all pharmaceuticals purchased using a revolving drug fund in Dessie Referral Hospital between January 1, 2013 to December 31, 2017, but medical equipment was excluded.

\section{Data Collection}

The annual consumption and expenditure incurred in each year were obtained from the electronic health commodity management information system and manual records in 
the hospital drug store. Pharmaceuticals were listed in Microsoft Excel Spreadsheet. VEN data were generated from the hospitals' comprehensive medication list developed by the drug and therapeutic committee.

\section{Data Collection Instrument}

A structured data collection tool or data abstraction format was used to collect quantitative data.

\section{Data Quality Assurance}

To assure the quality of the data, the structured abstraction tool was properly designed. The extracted data were examined for completeness and consistency during data collection, analysis, and interpretation. The pretest was conducted to test the extent to which the instrument measures what it supposed to measure in Borumeda Hospital. The reliability was determined by obtaining the proportion of systematic variation in the scale by determining the association between the score obtained from different administration on the scale and the scale yields consistence result and was therefore reliable. Moreover, principles of random event were employed for events which we do not know the outcome in advance.

\section{Data Analysis and Presentation}

The quantity of all purchased items was entered, the percentage of total value was calculated, and items were rearranged in descending order by value starting at the top with higher value. Then, the cumulative percentage by value, and items were computed, and cutoff points or boundaries for drugs $\mathrm{A}, \mathrm{B}$, and $\mathrm{C}$ were determined based on the Pareto principle. Finally, the ABC-VEN matrix was done. The data were analyzed using Microsoft Excel 2010, Statistical Package for Social Sciences version 20 and OriginPro 8 SR0 v8.0725 (B725).

\section{Operational Definitions}

- Pharmaceuticals: Health commodities consist of drugs, medical supplies, and laboratory reagents used for diagnosis, treatment, and prevention.

- Inventory management: Is A system/method of controlling stock transactions.

- ABC analysis: A method for classifying pharmaceuticals based on cost incurred.

- VEN analysis: A method of prioritizing pharmaceuticals based on public health importance as vital, essential, and normal.

\section{Results}

\section{$A B C$ Analysis}

A five-year ABC analysis of DRH on $313,359,432,380$, and 340 pharmaceuticals from 2013 to 2017 revealed that the peak procurement of items occurred in 2015. The ABC analysis showed that in 2013, 12.78\%, 20.77\%, and $66.45 \%$ of pharmaceuticals were class $\mathrm{A}, \mathrm{B}$, and $\mathrm{C}$, accounting for $69.64 \%, 19.98 \%$, and $10.38 \%$ of United States Dollar (USD) annual drug expenditures (ADE), respectively and fluconazole $200 \mathrm{mg}$, examination glove medium and normal saline amounted to $7.9 \%, 6.7 \%$, and $4.1 \%$ of $\mathrm{ADE}$ in 2013. In 2014, 75.93\%, 15.20\%, and $8.87 \%$ of ADE were consumed by $45.32 \%$ (55), $20.06 \%$ (72), and $64.62 \%$ (232) of class $\mathrm{A}, \mathrm{B}$, and $\mathrm{C}$ items (Table 1), while the sodium chloride $0.9 \%$ solution and examination glove medium amounted to $28.1 \%$ and $3.5 \%$ of ADE. The examination glove medium, ceftriaxone $1 \mathrm{~g}$ injection, and sodium chloride $0.9 \%$ solution amounting to $8.1 \%, 4.9 \%$, and $4.8 \%$ of ADE in 2015 , sodium chloride $0.9 \%$ solution, propranolol and propylthiouracil $100 \mathrm{mg}$ tablet amounted to $5.7 \%, 5.5 \%$, and $3.7 \%$ of ADE in 2016, and sodium chloride $0.9 \%$ solution, gauze surgical and examination glove medium amounted to $7.6 \%, 4.4 \%$, and $3.3 \%$ of total ADE.

The total five-year ABC analysis of Dessie Referral Hospital on 310 (17\%), 368 (20.17), and 1146 (62.83\%) of class $\mathrm{A}, \mathrm{B}$, and $\mathrm{C}$ items amounted to 2,088,612.1 (75.86\%), 434,429.06 (15.78), and 228,072.07 (8.37\%) of USD ADE, respectively. The Pareto curves for fiveyear $\mathrm{ABC}$ analysis are displayed in Figure 1.

\section{VEN Analysis}

DRH has an essential drug list (EDL) categorized by their respective VEN group and the list revised annually. The total five-year VEN analysis of DRH on 610 (34.56\%), 1125 (63.74), and $30(1.7 \%)$ of $\mathrm{V}, \mathrm{E}$, and $\mathrm{N}$ items amounted to $1,394,336.09$ (51.93\%), 1,275,548.19 (47.51), and 14,968.66 (0.56\%) of USD ADE, respectively. In the list, the majority of items were essential, and only a few were classified as normal. As shown in (Table 2), 303, 353, 422, 367, and 320 of purchased items were available in the list of drugs in DRH from 2013 to 2017, respectively. According to the study, 35.64\%, $63.37 \%$, and $0.99 \%$ of items were $\mathrm{V}, \mathrm{E}$, and $\mathrm{N}$ represented $47.31 \%, 52.59 \%$, and $0.1 \%$ of ADE, respectively in 2013 .

Trend analysis revealed that the pharmaceutical inventory cost increased (Figure 2$)$ and the total cost $(\beta=10.68$, 
Table I ABC Analysis of Pharmaceuticals at Dessie Referral Hospital (2013-2017)

\begin{tabular}{|c|c|c|c|c|c|}
\hline Year & Class & Number of Items & $\%$ of Items & ADE (USD) & $\%$ of ADE \\
\hline \multirow[t]{3}{*}{2013} & A & 40 & 12.78 & $236,852.12$ & 69.64 \\
\hline & B & 65 & 20.77 & $67,956.15$ & 19.98 \\
\hline & C & 208 & 66.45 & $35,313.01$ & 10.38 \\
\hline \multirow[t]{3}{*}{2014} & A & 55 & 15.32 & $339,938.91$ & 75.93 \\
\hline & B & 72 & 20.06 & $68,039.03$ & 15.20 \\
\hline & C & 232 & 64.62 & $39,720.41$ & 8.87 \\
\hline \multirow[t]{3}{*}{2015} & A & 75 & 17.36 & $425,030.07$ & 77.64 \\
\hline & B & 87 & 20.14 & $83,608.26$ & 15.27 \\
\hline & C & 270 & 62.50 & $38,802.70$ & 7.09 \\
\hline \multirow[t]{3}{*}{2016} & A & 73 & 19.21 & $491,045.38$ & 76.78 \\
\hline & B & 76 & 20.00 & $98,045.88$ & 15.33 \\
\hline & C & 231 & 60.79 & $50,493.57$ & 7.89 \\
\hline \multirow[t]{3}{*}{2017} & A & 67 & |9.7| & $595,745.63$ & 76.52 \\
\hline & B & 68 & 20.00 & II6,779.75 & 15.00 \\
\hline & C & 205 & 60.29 & $65,992.42$ & 8.48 \\
\hline
\end{tabular}

$\mathrm{p}=0.001)$, class $\mathrm{A}(\beta=8.68, \mathrm{p}=0.001)$, class $\mathrm{B}(\beta=1.27$, $\mathrm{p}=0.007)$, class $\mathrm{C}(\beta=0.72, \mathrm{p}=0.03)$, and $\mathrm{E}$ items $(\beta=$ $6.08, \mathrm{p}=0.01$ ) were found statistically significant, while $\mathrm{V}$ and $\mathrm{N}$ items were not found significant $(\mathrm{p}<0.05)$. The regression analysis also showed that the inventory cost of pharmaceutical in the hospital expected to increase and in 2025 , it is projected to be USD 1,619,351.79.
Although DRH has endorsed EDL and has been revised annually, some pharmaceuticals were purchased out of the EDL. The results showed that $1.78 \%, 1.17 \%, 3.05 \%, 1.75 \%$, and $1.03 \%$ of hospital ADE was incurred for procuring out of the list of pharmaceuticals from 2013 to 2017, respectively (Table 3). The $\mathrm{ABC}$ analysis showed that a total of 65 (3.56\%) items were purchased during the year 2013 to

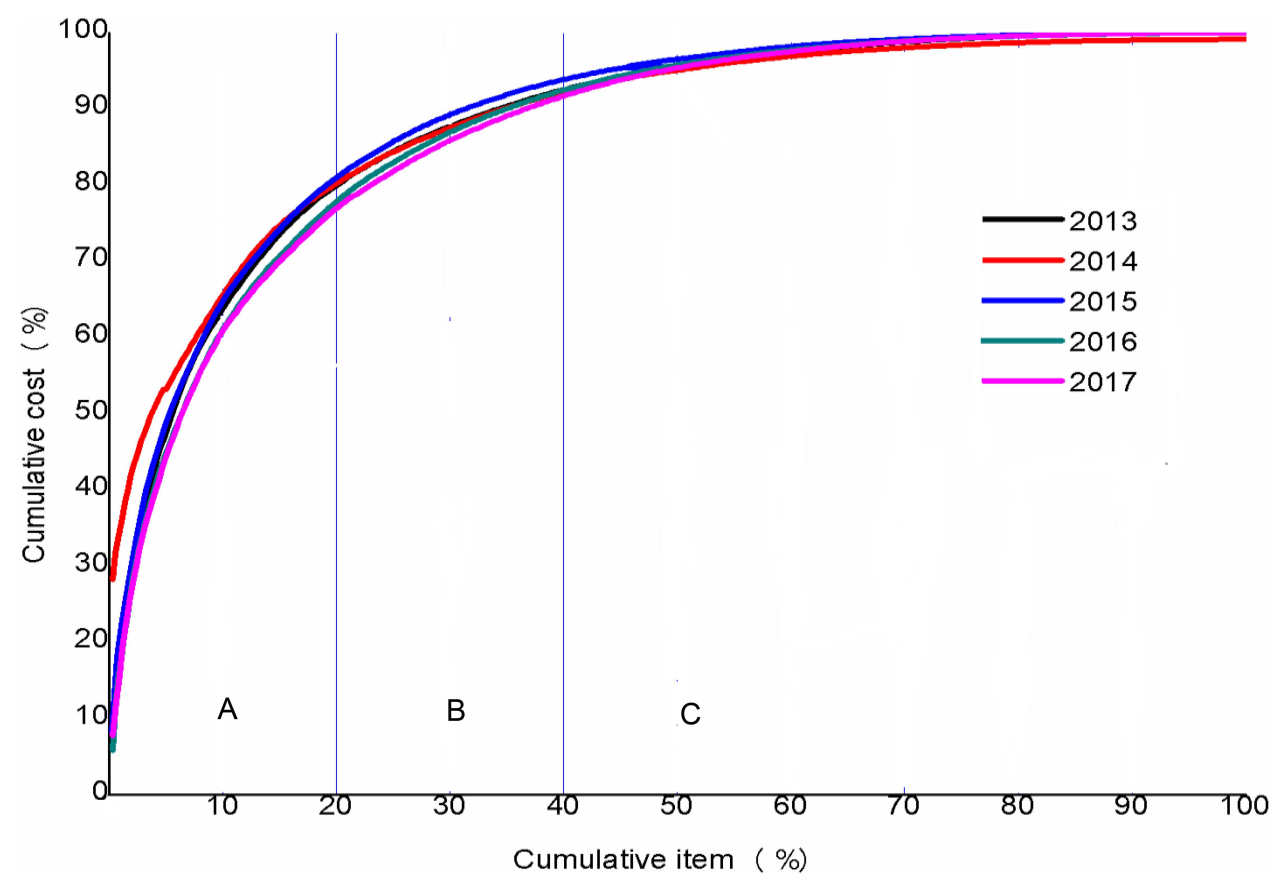

Figure I Total annual drug expenditure of pharmaceuticals at Dessie Referral Hospital (2013-2017). 
Table 2 VEN Analysis of Pharmaceuticals at Dessie Referral Hospital (2013-2017)

\begin{tabular}{|c|c|c|c|c|c|}
\hline Year & VEN & Number of Items & $\%$ of Items & ADE (USD) & $\%$ of ADE \\
\hline \multirow[t]{3}{*}{2013} & $\vee$ & 108 & 35.64 & $158,046.24$ & 47.31 \\
\hline & $\mathrm{E}$ & 192 & 63.37 & $175,693.18$ & 52.59 \\
\hline & $\mathrm{N}$ & 3 & 0.99 & 319.31 & 0.10 \\
\hline \multirow[t]{3}{*}{2014} & v & 154 & 43.63 & $295,311.21$ & 66.95 \\
\hline & $\mathrm{E}$ & 196 & 55.52 & $142,566.34$ & 32.32 \\
\hline & $\mathrm{N}$ & 3 & 0.85 & 3230.66 & 0.73 \\
\hline \multirow[t]{3}{*}{2015} & v & 135 & 31.99 & $290,611.22$ & 54.69 \\
\hline & E & 275 & 65.17 & $239,786.06$ & 45.12 \\
\hline & $\mathrm{N}$ & 12 & 2.84 & 1004.90 & 0.19 \\
\hline \multirow[t]{3}{*}{2016} & v & 118 & 32.15 & $294,917.69$ & 46.96 \\
\hline & $E$ & 246 & 67.03 & $332,937.40$ & 53.01 \\
\hline & $\mathrm{N}$ & 3 & 0.82 & 221.56 & 0.04 \\
\hline \multirow[t]{3}{*}{2017} & V & 95 & 29.69 & $355,449.72$ & 47.38 \\
\hline & $\mathrm{E}$ & 216 & 67.50 & $384,565.20$ & 51.26 \\
\hline & $\mathrm{N}$ & 9 & 2.81 & $10,192.22$ & 1.36 \\
\hline
\end{tabular}

2017, accounting for 68,671.26 (2.5\%) ADE of the hospital, which depicted an increase in successive years. The majority of the items were class C. Plastic bed sheet, haem up syrup, hepatitis b vaccine, meloxicam $15 \mathrm{mg}$ tablet, intraocular lens, ferric ammonium citrate + folic acid + cyanocobalamin + cupric sulfate + manganese sulfate $(160 \mathrm{mg}+0.5 \mathrm{mg}+$ $7.5 \mathrm{mcg}+30 \mathrm{mcg}+30 \mathrm{mcg}$ ), enoxaparin injection $40 \mathrm{mg}$ / $0.4 \mathrm{~mL}$, adhesive plaster zinc oxide $5 \mathrm{~cm} * 5 \mathrm{~cm}$, risperidone tablet $2 \mathrm{mg}$, and acyclovir $250 \mathrm{mg}$ injection were the products purchased out of EDL and took a higher percentage of ADE.

Out of total procured pharmaceuticals, drugs accounts $187(16.3 \%), 241(21 \%)$, and $721(62.8 \%)$ of class A, B, and $\mathrm{C}$ with the $\mathrm{ADE}$ of $37,061,382.19$ (75.5\%), $7,862,577.79(16.1 \%)$, and 4,039,510.35 (8.3\%) of respectively and $277(25.3 \%) \mathrm{V}, 802(73.2 \%) \mathrm{E}$, and $17(1.6 \%) \mathrm{N}$ used 22,708,488.88 (47.3\%), 25,187,476.50 (52.4\%), and $143,006.23(0.3 \%)$ of drugs incurred cost. Medical supplies, chemical and reagents constituted 99 (22.1\%), and $162(38.5 \%)$ of A, 95 (21.3\%), and 248 (58.9\%) of B and $253(56.6 \%)$, and $11(2.6 \%)$ of C items with 17,140,576.42 $(79.4 \%)$, and $14,625,623.78(53.3 \%)$, and $3,135,800.14$ $(14.5 \%)$, and $12,551,509.88(45.7 \%)$, and $1,319,609.05$ $(6.1 \%)$, and $262,589.21(1 \%)$ of budget, respectively (Figure 3).

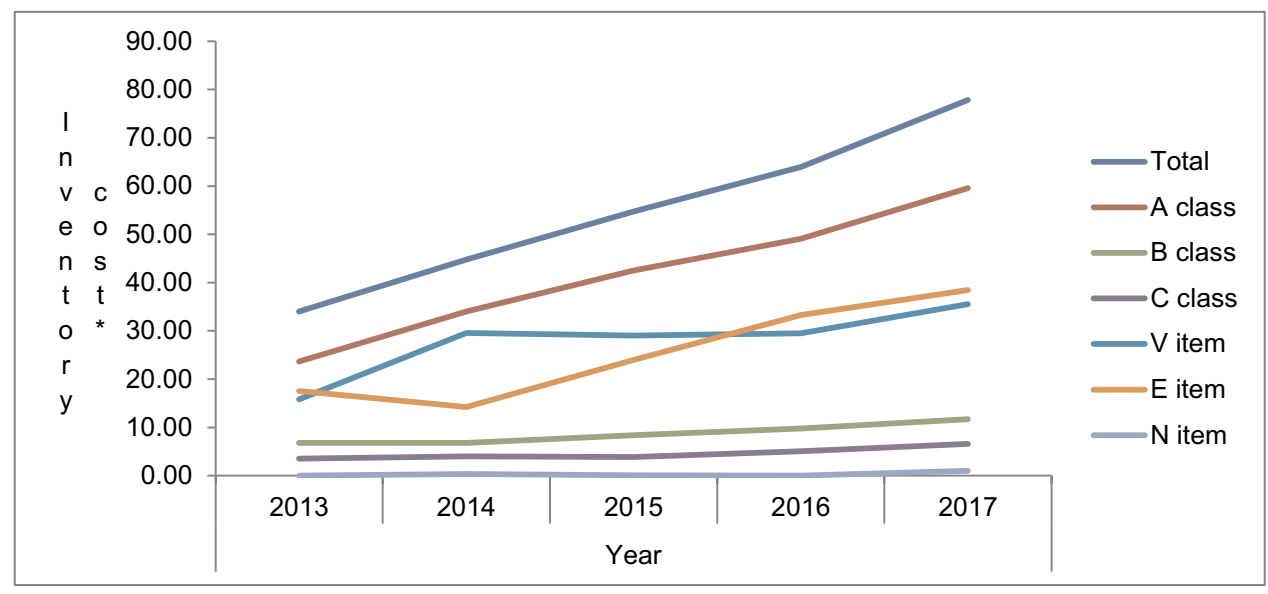

*Inventory cost is in hundred thousand

Figure 2 Trends in drug expenditure of pharmaceuticals at Dessie Referral Hospital (2013-2017). 


\section{ABC-VEN Matrix}

Total ABC and VEN analyses of Dessie Referral Hospital revealed that $139(7.88 \%), 132(7.48 \%)$, and $339(19.21 \%)$ of $\mathrm{AV}, \mathrm{BV}$, and $\mathrm{CV}$ items utilized 1,168,558.18 (43.52\%), $148,284.38$ (5.52\%), and 77,493.53 (2.89\%) ADE, respectively while 159 (9.01\%), 225 (12.75\%), and 741 (41.98\%) of items were $\mathrm{AE}, \mathrm{BE}$, and $\mathrm{CE}$ items amounting to $865,944.58(32.75 \%), 269,006.22(10.02 \%)$, and $140,595.25$ (5.24\%) ADE, respectively. The remaining 2 $(0.11 \%), 1(0.06 \%)$, and $27(1.53 \%)$ of items amounting to $8124.97(0.3 \%), 2359.72(0.09 \%)$, and $4483.72(0.17 \%)$ of $\mathrm{ADE}$ were $\mathrm{AN}, \mathrm{BN}$, and $\mathrm{CN}$, respectively. In 2103, 18 (46.15\%), 21 (53.85\%) of AV and AE, utilized 120,178.02 (51.66\%), 112,467.58 (48.34\%) of ADE, respectively, while CV, CE and CN accounts 68 (34\%), 129 (64.5\%), and $3(1.5 \%)$ of pharmaceuticals with $14,445.97$ (41.92\%), $19,692.41 \quad(57.15 \%)$, and $319.31(0.93 \%)$ of $\mathrm{ADE}$ (Table 4).

The five-year pharmaceutical analysis showed that categories I, II, and III pharmaceuticals accounted for
771 (43.68\%), $967(54.79 \%)$, and $27(1.53 \%)$ of items with their respective drug expenditures of USD 2,268,405.64 (84.49), 411,961.18 (15.34\%), and 4483.97 (0.17\%). The ABC-VEN matrix showed that category I included $\mathrm{AV}, \mathrm{AE}, \mathrm{AN}, \mathrm{BV}$, and $\mathrm{CV}$ like Hydralazine, insulin soluble and regular, intravenous fluids, sulfamethoxazole + trimethoprim tablet, ceftriaxone $1 \mathrm{~g}$ injection, tetanus antitoxin, carbamazepine, cimetidine $20 \mathrm{mg}$ injection, and from supplies cut gut and syringe constituted $43.68 \%$ of items and $84.49 \%$ of USD ADE. Category II, which includes matrices $\mathrm{BE}, \mathrm{CE}$, and $\mathrm{BN}$, constitute $54.76 \%$ and $15.34 \%$, and category III like chloropheniramine tablets, talk powder, fluconazole suspension, and infusion includes matrix $\mathrm{CN} 1.53 \%$ and $0.17 \%$ of items and ADE, respectively (Table 5).

\section{Discussion}

Scientific drug inventory management techniques are necessary for efficient and effective healthcare delivery. ABC classifications allow the inventory manager to assign priorities for

Table 3 Number of Pharmaceuticals Purchased Out of EDL at Dessie Referral Hospital (2013-2017)

\begin{tabular}{|c|c|c|c|c|c|}
\hline Year & Class & Number of Items & $\%$ of Items & ADE (USD) & $\%$ of ADE \\
\hline 2013 & $\begin{array}{l}\text { A } \\
\text { B } \\
\text { C } \\
\text { Total }\end{array}$ & $\begin{array}{l}1 \\
1 \\
8 \\
10\end{array}$ & $\begin{array}{l}0.32 \\
0.32 \\
2.56 \\
3.19\end{array}$ & $\begin{array}{l}4206.50 \\
1002.33 \\
855.88 \\
6064.72\end{array}$ & $\begin{array}{l}1.24 \\
0.29 \\
0.25 \\
1.78\end{array}$ \\
\hline 2014 & $\begin{array}{l}\text { A } \\
\text { B } \\
\text { C } \\
\text { Total }\end{array}$ & $\begin{array}{l}2 \\
0 \\
5 \\
7\end{array}$ & $\begin{array}{l}0.56 \\
- \\
1.39 \\
1.95\end{array}$ & $\begin{array}{l}6220.93 \\
- \\
382.00 \\
6602.93\end{array}$ & $\begin{array}{l}1.39 \\
- \\
0.09 \\
1.47\end{array}$ \\
\hline 2015 & $\begin{array}{l}\text { A } \\
\text { B } \\
\text { C } \\
\text { Total }\end{array}$ & $\begin{array}{l}1 \\
2 \\
13 \\
16\end{array}$ & $\begin{array}{l}0.23 \\
0.46 \\
3.01 \\
3.70\end{array}$ & $\begin{array}{l}5721.26 \\
2317.53 \\
8671.22 \\
16,710.01\end{array}$ & $\begin{array}{l}1.05 \\
0.42 \\
1.58 \\
3.05\end{array}$ \\
\hline 2016 & $\begin{array}{l}\text { A } \\
\text { B } \\
\text { C } \\
\text { Total }\end{array}$ & $\begin{array}{l}1 \\
0 \\
11 \\
12\end{array}$ & $\begin{array}{l}0.26 \\
- \\
2.89 \\
3.16\end{array}$ & $\begin{array}{l}5332.85 \\
- \\
5850.11 \\
11,182.96\end{array}$ & $\begin{array}{l}0.83 \\
- \\
0.91 \\
1.75\end{array}$ \\
\hline 2017 & $\begin{array}{l}\text { A } \\
\text { B } \\
\text { C } \\
\text { Total }\end{array}$ & $\begin{array}{l}3 \\
6 \\
11 \\
20\end{array}$ & $\begin{array}{l}0.88 \\
1.76 \\
3.24 \\
5.88\end{array}$ & $\begin{array}{l}13,502.79 \\
10,288.08 \\
4519.78 \\
28,310.65\end{array}$ & $\begin{array}{l}1.73 \\
1.32 \\
0.58 \\
1.03\end{array}$ \\
\hline Total & $\begin{array}{l}\text { A } \\
\text { B } \\
\text { C } \\
\text { Total }\end{array}$ & $\begin{array}{l}8 \\
9 \\
48 \\
65\end{array}$ & $\begin{array}{l}0.44 \\
0.49 \\
2.63 \\
3.56\end{array}$ & $\begin{array}{l}34,984.32 \\
13,607.95 \\
20,279.00 \\
68,871.27\end{array}$ & $\begin{array}{l}1.27 \\
0.49 \\
0.74 \\
2.50\end{array}$ \\
\hline
\end{tabular}




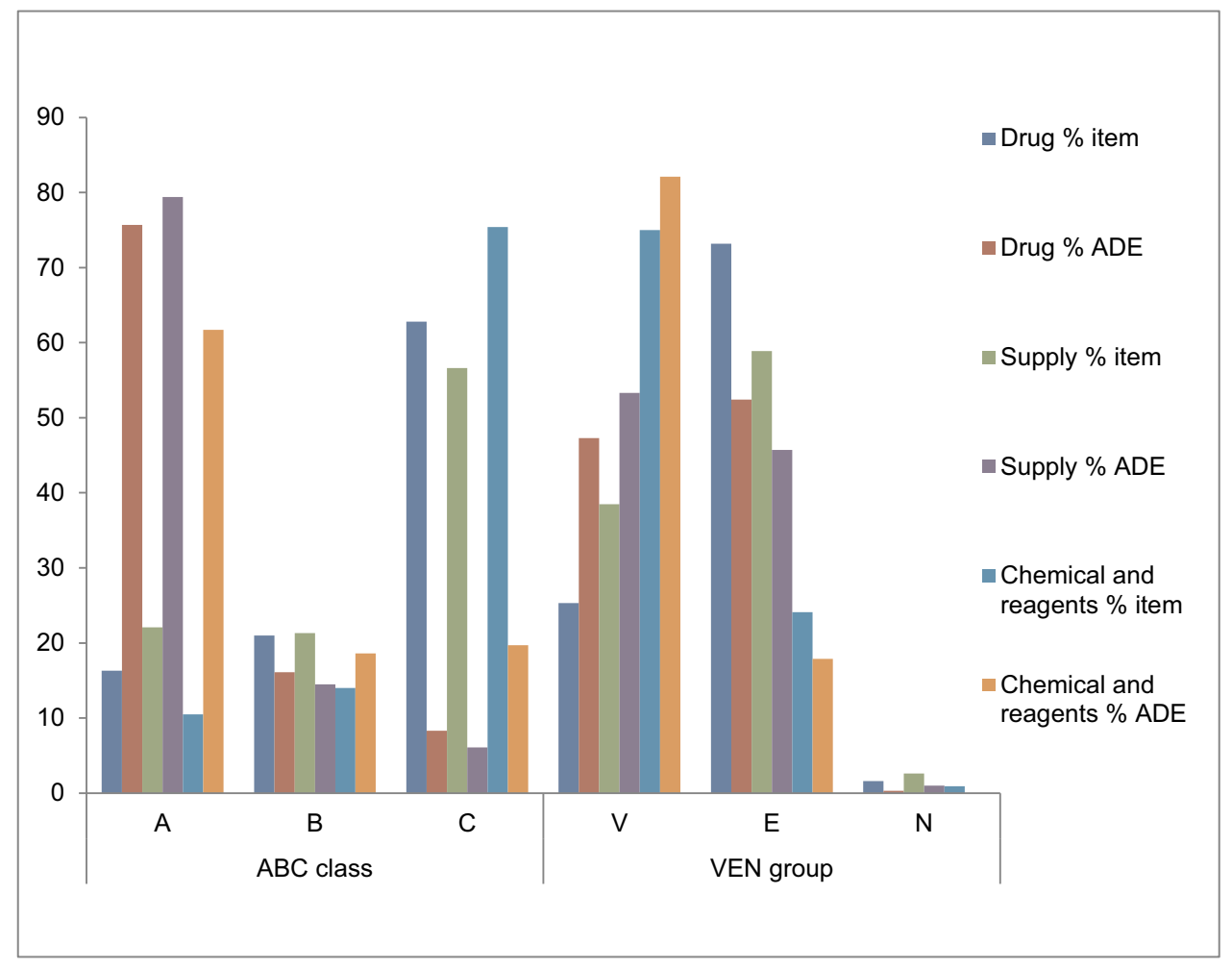

Figure 3 Total $A B C$ and VEN analysis of pharmaceuticals of Dessie Referral Hospital (2013-2017).

inventory control and then to promote effective drug inventory management with minimal monetary resources while maintaining the required safety stocks of high-priority drugs and reduce the frequency of drug supply shortages. ${ }^{22}$

The study assessed the ABC-VEN matrix analysis of pharmaceutical inventories in the Dessie Referral Hospital. The result indicated that pharmaceutical inventories called for due attention because few items (17\%) utilize the majority of ADE (75.86\%) of pharmacy. The consumption rate, storage condition, and level of safety stock should always be checked to have a steady stock level.

ABC analysis also showed similar items like:- antibiotics like ceftriaxone $1 \mathrm{~g}$ injection: fluids like sodium chloride $0.9 \%$ solution and ringer lactate: supplies like examination glove medium and gauze surgical, and others like propranolol and propylthiouracil lay in the same category (A) in all five years. This might be due to higher consumption, poor inventory management, and/or elevated price of pharmaceuticals, but examination glove medium might be intensively used by students because the Dessie Referral Hospital provides referral-level care and served as clinical attachment site health sciences students.

The present study showed that out of 1824 drugs, $17 \%$ belonged to category A, which consumed around $75.86 \%$ of ADE. The drugs belonging to category A require strict managerial control, accurate data-driven forecasting of demand, close check on budgetary control, minimum safety stock, staggered purchase orders, frequent stock taking and judicious purchasing, stocking, issue, and inspection policy. $^{23}$

Categories B and $\mathrm{C}$ accounted for $20.18 \%$ and $62.83 \%$ of items, amounting to $15.78 \%$ and $8.31 \%$ of $\mathrm{ADE}$ of pharmacy. Category B drugs required moderate control, whereas category $\mathrm{C}$ required minimum control measures for order and purchase. $\mathrm{C}$ class items can be maintained with looser control and with a high safety stock level. In addition to other management procedures, ABC classifications can be used to design counting schemes. Perpetual or cyclic counting could be applied to A and B class items whereas annual counting could be done on $\mathrm{C}$ items. ${ }^{24}$

Comparing present study results with similar studies around the world revealed considerable differences (Table 6) in percentage of items procured. The differences could most probably be due to the fact that all these hospitals differed in level of health care, prevalence of disease conditions, professional skills, and financial power. The study findings were comparable with black line specialized hospital study ${ }^{25}$ and with a certain 


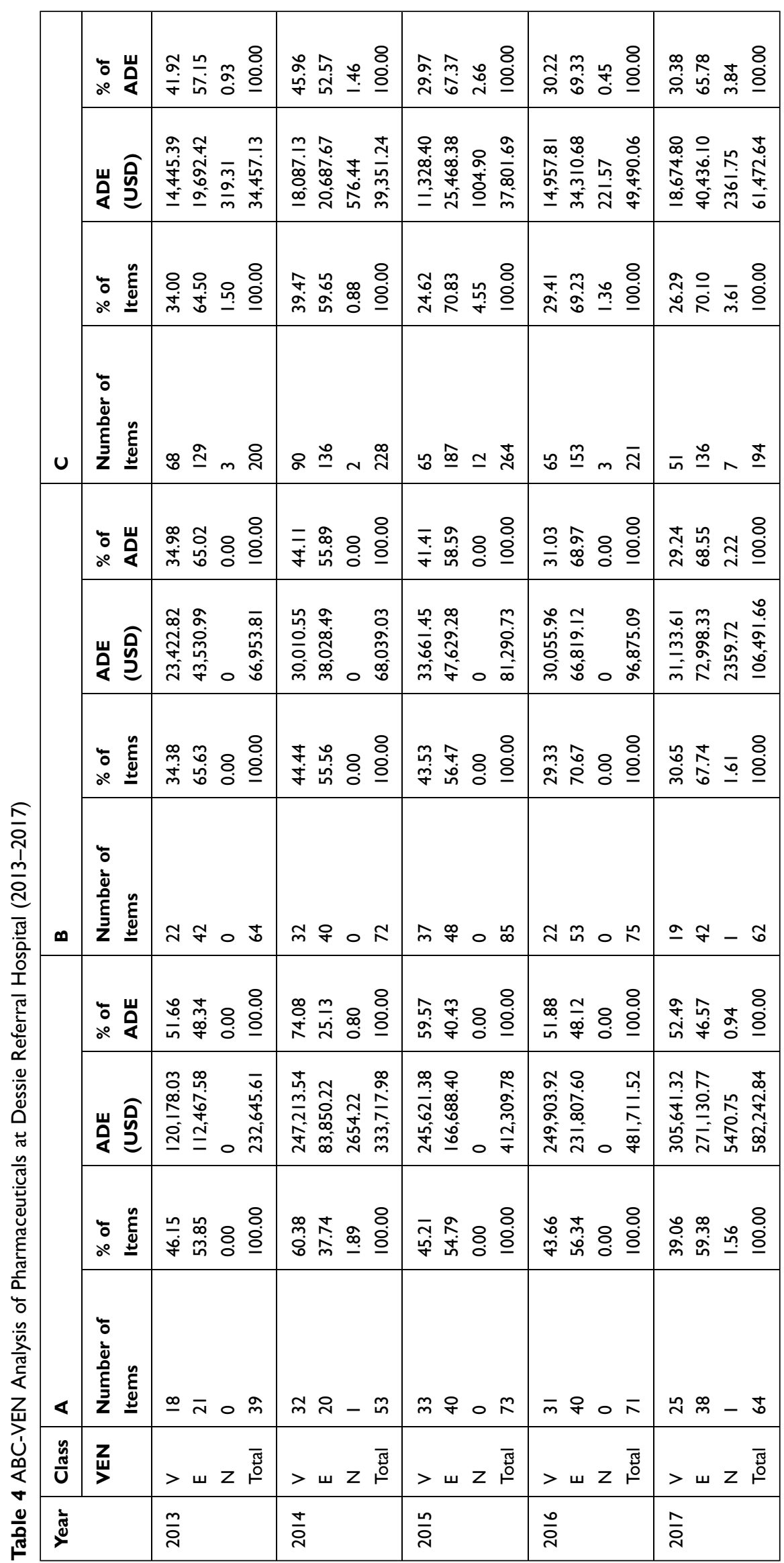


Table 5 ABC-VEN Analysis of Pharmaceuticals at Dessie Referral Hospital by Category (2013-2017)

\begin{tabular}{|c|c|c|c|c|c|}
\hline Year & Category & Number of Items & $\%$ of Items & ADE & $\%$ of $A D E$ \\
\hline \multirow[t]{4}{*}{2013} & Category I & 129 & 42.57 & $270,513.82$ & 80.98 \\
\hline & Category 2 & 171 & 56.44 & $63,223.41$ & 18.93 \\
\hline & Category 3 & 3 & 0.99 & 319.31 & 0.10 \\
\hline & Total & 303 & 100.00 & $334,056.55$ & 100.00 \\
\hline \multirow[t]{4}{*}{2014} & Category I & 175 & 49.58 & $38 I, 815.66$ & 86.56 \\
\hline & Category 2 & 176 & 49.86 & $58,716.16$ & 13.31 \\
\hline & Category 3 & 2 & 0.57 & 576.44 & 0.13 \\
\hline & Total & 353 & 100.00 & $44 I, 108.25$ & 100.00 \\
\hline \multirow[t]{4}{*}{2015} & Category I & 175 & 41.47 & $457,299.63$ & 86.06 \\
\hline & Category 2 & 235 & 55.69 & $73,097.66$ & 13.76 \\
\hline & Category 3 & 12 & 2.84 & 1004.90 & 0.19 \\
\hline & Total & 422 & 100.00 & $531,402.19$ & 100.00 \\
\hline \multirow[t]{4}{*}{2016} & Category I & 158 & 43.05 & $526,725.29$ & 83.86 \\
\hline & Category 2 & 206 & 56.13 & $101,129.80$ & 16.10 \\
\hline & Category 3 & 3 & 0.82 & 221.57 & 0.04 \\
\hline & Total & 367 & 100.00 & $628,076.66$ & 100.00 \\
\hline \multirow[t]{4}{*}{2017} & Category I & 134 & 41.88 & $632,051.24$ & 84.25 \\
\hline & Category 2 & 179 & 55.94 & $115,794.15$ & 15.43 \\
\hline & Category 3 & 7 & 2.19 & 2361.75 & 0.31 \\
\hline & Total & 320 & 100.00 & $750,207.14$ & 100.00 \\
\hline
\end{tabular}

deviation from Pareto's principle in a similar hospital study. $^{26}$ This similarity might be because all health institutions are forced to purchase primarily pharmaceuticals from sole supplier Pharmaceutical Fund and Supply Agency. $^{27}$

The results were also within the same range indicated by Pareto as compared to studies conducted in Kenyatta Nationals Hospital by Kivoto (2016), ${ }^{28}$ tertiary care teaching hospital study by Poorwa et $\mathrm{al}^{29}$ Turkey University Hospital study by Ygggt, ${ }^{30}$ and GünerGören, Dağdeviren study in Turkey. ${ }^{31}$

$\mathrm{ABC}$ analysis of the pharmacy store of a tertiary care academic institute of northern India $11.23 \%, 24.60 \%$, and $75.4 \%$ items as $\mathrm{A}, \mathrm{B}$, and $\mathrm{C}$ category items, respectively, accounting for $70.19 \%, 19.83 \%$, and $9.98 \%$ of ADE were also complying with the present study findings. ${ }^{32}$ The difference in the magnitude of the total budget might be attributed to differences in patient load, level of health facility, health institutions financial power, and pharmaceutical policy.

Dessie Referral Hospital spends 64.98\%, 28.66\%, and $6.36 \%$ of ADE constituted $62.99 \%, 24.51 \%$, and $12.50 \%$ of drugs, medical supplies, and laboratory reagents, respectively. This indicated that a large amount of budget had invested for drugs, supplies, and laboratory reagents, respectively. The total result was consistent with the findings of each separate year.

VEN analysis showed that $34.56 \%$ of items amounting to $51.93 \%$ of ADE were $\mathrm{V}, 63.71 \%$ of items amounting to $47.51 \%$ of $\mathrm{ADE}$ were $\mathrm{E}$, and $1.7 \%$ of items amounting to $0.56 \%$ of ADE were N. Vital items are life-saving drugs and cannot be substituted as a result the stock out of which cannot be tolerated and required sufficient budget. The absence of essential drugs could be tolerated for short periods of time and can be substituted by $\mathrm{V}$ items, while in the absence of $\mathrm{N}$ items could be tolerated for longer periods of time. ${ }^{33}$ During budget assignment and inventory control, $\mathrm{V}, \mathrm{E}$, and $\mathrm{N}$ took priority in their respective order, and the maximum stock of $\mathrm{V}$ and minimum stock of $\mathrm{N}$ could be maintained at all times.

As shown above in Table 6, the percentage of $\mathrm{V}, \mathrm{E}$, and $\mathrm{N}$ items DRH was lower than that of the black line hospital. This might indicate that DRH invested a huge amount of budget for essential than vital items. Efficient utilization of budget has been observed in normal items as compared to studies in Kenya, India, and Turkey. The findings of the present study comparable with similar study on ABC and VEN analysis of the pharmacy store of a tertiary care 
Table 6 Comparison of ABC-VEN Matrix Analysis of Studies by Various Authors

\begin{tabular}{|c|c|c|c|c|c|c|c|c|c|c|c|c|c|}
\hline \multirow[t]{2}{*}{$\begin{array}{l}\text { Analysis } \\
\text { Parameters }\end{array}$} & \multirow[t]{2}{*}{ Category } & \multicolumn{2}{|c|}{$\begin{array}{l}\text { Sefinew et al } \\
(2016)^{26}\end{array}$} & \multicolumn{2}{|c|}{$\begin{array}{l}\text { Abate } \\
(2013)^{13}\end{array}$} & \multicolumn{2}{|c|}{$\begin{array}{l}\text { Kivoto } \\
(2016)^{28}\end{array}$} & \multicolumn{2}{|c|}{$\begin{array}{l}\text { Poorwa et al } \\
(2013)^{29}\end{array}$} & \multicolumn{2}{|c|}{$\begin{array}{l}\text { GünerGören } \\
\text { et al }(2017)^{31}\end{array}$} & \multicolumn{2}{|c|}{$\begin{array}{l}\text { Ygggt } \\
(2016)^{30}\end{array}$} \\
\hline & & $\begin{array}{l}\% \text { of } \\
\text { Items }\end{array}$ & $\begin{array}{l}\% \text { of } \\
\text { ADE }\end{array}$ & $\begin{array}{l}\% \text { of } \\
\text { Items }\end{array}$ & $\begin{array}{l}\% \text { of } \\
\text { ADE }\end{array}$ & $\begin{array}{l}\% \text { of } \\
\text { Items }\end{array}$ & $\begin{array}{l}\% \text { of } \\
\text { ADE }\end{array}$ & $\begin{array}{l}\% \text { of } \\
\text { Items }\end{array}$ & $\begin{array}{l}\% \text { of } \\
\text { ADE }\end{array}$ & $\begin{array}{l}\% \text { of } \\
\text { Items }\end{array}$ & $\begin{array}{l}\% \text { of } \\
\text { ADE }\end{array}$ & $\begin{array}{l}\% \text { of } \\
\text { Items }\end{array}$ & $\begin{array}{l}\% \text { of } \\
\text { ADE }\end{array}$ \\
\hline \multirow[t]{3}{*}{$A B C$ class } & A & 14.63 & 78.11 & 1.57 & 78.17 & 13.6 & 79.9 & 13.4 & 69.1 & 10 & 80 & 12 & 70 \\
\hline & B & 19.1 & 13.78 & 14.56 & 16.73 & 16.5 & 15.1 & 16.5 & 19.2 & 23 & 17 & 21 & 20 \\
\hline & C & 66.27 & 8.11 & 83.9 & 5.1 & 69.9 & 5 & 70.1 & 11.7 & 67 & 3 & 67 & 10 \\
\hline \multirow[t]{3}{*}{ VEN group } & V & 77.51 & 91.57 & & 87.90 & 22.81 & 33.7 & 50.9 & 55.2 & 24.2 & 43.08 & 11 & 20 \\
\hline & $E$ & 22.24 & 8.42 & & 11.97 & 53.2 & 58.4 & 40.2 & 41.5 & $|4.0|$ & 19.22 & 68 & 54 \\
\hline & $N$ & 0.25 & 0.01 & & 0.13 & 23.92 & 7.8 & 8.9 & 3.3 & 61.78 & 37.7 & 21 & 26 \\
\hline \multirow[t]{3}{*}{ Category } & I & 79.35 & 96.36 & & 87.90 & 31 & 84.9 & 57 & 85.3 & 29.94 & 84.81 & 20 & 78 \\
\hline & II & 20.40 & 3.63 & & 11.97 & 47.7 & 14 & 35 & 14.2 & 24.84 & 13.39 & 67 & 17 \\
\hline & III & 0.25 & 0.01 & & 0.13 & 21.3 & II & 8 & 0.5 & 45.22 & 1.8 & 13 & 5 \\
\hline \multicolumn{2}{|l|}{ Out of EDL } & 13.84 & 5.69 & 18.5 & 1.91 & & & & & & & & \\
\hline
\end{tabular}

teaching, research, and referral healthcare institute of India showed $12.11 \%, 59.38 \%$, and $28.51 \%$ items as V, E, and $\mathrm{N}$ category items, respectively, accounting for $17.14 \%$, $72.38 \%$, and $10.48 \%$ of ADE of the pharmacy. ${ }^{34}$

Generally, there was a high variation in the percentage of VEN items in all studies. This could be because different institutes have different service profiles, depending on the specialty services available and differed in their policies of classifying drugs into VEN.

The availability of vital pharmaceuticals gradually decreased from $43.63 \%$ (2014) to $29.69 \%$ (2017) relative to hospital EDL. ${ }^{35}$ This showed that the availability of vital medication was poor due to financial constraints or inefficient budget utilization during prioritization. The regular and consistent availability of the necessary medicines is the topmost priority for any hospital. The shortage of pharmaceuticals adversely affected the quality of health care and the condition could be more severe if stock out is prolonged.

According to the World Health Organization (WHO), the availability of medicines is less than $60 \%$ in the public sector across WHO regions, ranging from $32 \%$ in the Eastern Mediterranean region to $58 \%$ in the European region. ${ }^{36}$ In the poorest countries of Africa and Asia, Nearly $50 \%$ of the population lacks such access. The situation is even worse in many poor African countries, where $50-60 \%$ of the population lacks access to medications. $^{37}$

A study conducted in primary public health facilities in Gondar town showed that the overall average availability of essential medicines was $91 \%$ and the mean duration of stock out of tracer medicines of the health facilities in the six months period was 30.5 days. ${ }^{38}$ A similar study by Ewen et al (2017) revealed that the mean availability of medicines was $73 \%$ in the private sector. ${ }^{39}$ Other study carried out in southwest Ethiopian also showed that $55.65 \%$ of essential medicines were available. ${ }^{40}$

In health institutions where a closed formulary system is practiced, procurement should be adhered to EDL. This would save a substantial amount of financial resources and avoid the availability of unnecessary items. In the total five years, $3.6 \%$ of items with $2.5 \%$ of ADE were used for items that were not available from EDL. This shows that either the EDL was not comprehensive or a sign of poor procurement. The findings were low compared to those of a study conducted in a black line specialized hospital.

The ABC-VEN matrix shows that category I included $\mathrm{AV}, \mathrm{AE}, \mathrm{AN}, \mathrm{BV}$, and $\mathrm{CV}$ constituted $43.68 \%$ of items and $84.49 \%$ of ADE. Category II, which includes matrices BE, $\mathrm{CE}$, and $\mathrm{BN}$, constituted $54.76 \%$, and $15.34 \%$, and category III matrix contained $\mathrm{CN} 1.53 \%$ and $0.17 \%$ of items and ADE, respectively. A marked difference in the percentage of items under categories I and II of pharmaceutical were observed between black line specialized hospitals and the present study because of the variation in giving prioritization of pharmaceuticals expenditures in the VEN group, but similar items like fluids, examination gloves, and insulin were laid under category I.

As compared to other studies presented above in Table 6, the percentage of items and $\mathrm{ADE}$ of pharmaceuticals for 
category III were small. A similar study conducted by Pirankar et al indicated that $18.44 \%$ of drugs were classified as category I and accounted for $71.95 \%$ of ADE. The remaining $48.94 \%$ and $32.62 \%$ of drugs were considered as category II and category III drugs and were found to consume $24.39 \%$ and $3.66 \%$ of ADE, respectively. ${ }^{41}$

Category $\mathrm{I}$ is the highest priority group, needing the greatest attention because it consists of vital or essential drugs with high cost. They should always be available in stock, and a low safety stock should be maintained. Strict control is mandatory for category I drugs in keeping budgets and their availability. Moderate attention should be given to category II as they contained essential and desirable drugs having a lower cost than category I. Large order can be made for these drugs. Loose attention could be given to category III. Since this category was cheap, ordered can be placed once or twice in a year to save ordering cost at a reasonable carrying cost. ${ }^{42}$

$\mathrm{ABC}$ analysis reduce inventory levels and costs by arranging for more frequent purchase or delivery of smaller quantities of class A items, seek major cost reductions by finding lower prices on class A items, reduce inventory of items that have limited use, but cost the system large amounts of money, provide information for choosing the most cost-effective alternatives and finding opportunities for therapeutic substitution and pharmacoeconomic analysis. ${ }^{43}$ VEN analysis prioritize medicines based on their critically. ${ }^{19}$ A combination of ABC and VEN analysis made a comparison between the ABC and VEN groups in order to identify whether there is relatively high expenditure on low priority drugs. ${ }^{44}$

Apart from the ABC/VEN analysis, the hospital should use another methods of inventory analysis like classifying items as fast moving, slow moving and non-moving based on their movement from the store, classifying by value of inventory available on a particular date in the store as high, moderate and low stock values, ${ }^{45}$ classification based on scarce to procure, difficult to procure, and easy to procure, seasonal requirement and unit price of items as high, medium and low. ${ }^{46}$

\section{Conclusion}

Dessie Referral Hospital invested spent a significant amount of the budget for procuring class A pharmaceutical. Category A items accounted for fewer drugs and the highest costs, which pinpointed the need for strict inventory control to prevent wastage and accumulation of capital in buffer stocks. Nearly half of the ADE was invested for vital items and more priority should be given, and sufficient stock could be maintained at all times. Category I items constituted vital and essential drugs having high cost. Despite they should always be available in stock, a low safety stock should be maintained. The total cost, A class, B class, C class, and $\mathrm{E}$ items was found statistically significant. ABC-VEN analysis should be performed strictly in the hospital at the end of each fiscal year, and the findings could be used for taking corrective measures in the inventory and generating order for the next procurement period.

\section{Abbreviations}

$\mathrm{ABC}$, always, better, and control; ADE, annual drug expenditure; EDL, essential drug list; USD, United States Dollar; VEN, vital, essential, and normal; WHO, World Health Organization.

\section{Data Sharing Statement}

The datasets are available from the corresponding author upon reasonable request.

\section{Ethical Considerations}

Before commencing data collection, an ethical clearance letter was obtained from the Ethics Review Committee of the College of Medicine and Health Sciences, Wollo University (CMHS/3050/10). The study was then conducted after getting permission from the Dessie Referral Hospital. Information regarding the purpose of the study, why and how they were selected, and what will be expected from them were provided. Then, records of pharmaceuticals transaction in the pharmacy store were reviewed and all data were kept confidential. The study has no any anticipated risk. Informed consent was not required and the consent was restricted to hospital pharmacy store. The study was done with the consideration and compliance with declaration of Helsinki.

\section{Acknowledgment}

The authors would like to acknowledge Wollo University.

\section{Author Contributions}

All authors made a significant contribution to the work reported, whether that is in the conception, study design, execution, acquisition of data, analysis and interpretation, or in all these areas; took part in drafting, revising or critically reviewing the article; gave final approval of the version to be published; have agreed on the journal to 
which the article has been submitted; and agree to be accountable for all aspects of the work.

\section{Disclosure}

The authors declare that they have no potential competing interests.

\section{References}

1. Santhi G, Karthikeyan K. Recent review article on pharmaceutical inventory models. Int J Pharmtech Res. 2016;9(5):434-443.

2. Fredric P. Inventory control in pharmaceutical supply chain. Available from: https://www.linkedin.com/pulse/inventory-controlpharmaceutical-supply-chain-pinto. Accessed August 31, 2020.

3. Renukadevi R. A study of inventory control practices in the department of stores of a tertiary care hospital, 2010. Available from: http:// www.rguhs.ac.in/cdc/onlinecde/uploads/15_HM07_25373.doc. Accessed August 31, 2020.

4. Surabhi D, Arun K, Preeti K. Inventory management: a tool of identifying items that need greater attention for control. $J$ Pharm Innov. 2012;1(7):125-129.

5. Ilma NR, Mursyid HB. Pharmaceutical inventory management issues in hospital supply chains. Management. 2013;3(1):1-5. doi:10.5923/j. mm.20130301.01

6. Thawani VR, Turankar AV, Sontakke SD, et al. Economic analysis of drug expenditure in government medical college hospital, Nagpur. Indian J Pharmacol. 2004;36(1):15.

7. Cameron A, Ewen M, Ross-Degnan D, Ball D, Laing R. Medicine Prices, Availability, and Affordability in 36 Developing and MiddleIncome Countries: A Secondary Analysis. 2008. doi:10.1016/S01406736(08)61762-6

8. Kagashe G, Massawe E. Medicine stock out and inventory management problems in public hospitals in Tanzania: a case of dares salaam region hospitals. Int J Pharm. 2012;2(2):252-259.

9. Leung N-HZ, Chen A, Yadav P, Gallien J. The impact of inventory management on stock-outs of essential drugs in Sub-Saharan Africa: secondary analysis of a field experiment in Zambia. PLoS One. 2016;11(5):e0156026. doi:10.1371/journal.pone.0156026

10. MarfoOsori K, Hamilton B, Birch F, Nunoo N, Torrey S, Soghoian S. Essentials for emergency care: lessons from an inventory assessment of an emergency center in Sub-Saharan Africa. Afr J Emerg Med. 2014;4(4):174-177. doi:10.1016/j.afjem.2014.05.003

11. Khalid H, Lina A-Q. Healthcare logistics cost optimization using a multi-criteria inventory classification. Proceedings of the 2011 International Conference on Industrial Engineering and Operations Management; January 22-24, 2011; Kuala Lumpur, Malaysia.

12. Susan W, Joseph O. An assessment of the effects of inventory management procedures on performance of Kengen. Int $J$ Sci Res Publ. 2015;5(10).

13. Abate R. Managing medicines in the hospital pharmacy:logistics inefficiencies. Proceedings of the World Congress on Engineering and Computer Science; October 23-25, 2013; San Francisco, USA.

14. Evaluating hospital pharmacy inventory management and revenue cycle processes. White paper guidance for healthcare internal auditors. Available from: https://www.ahia.org/assets/Uploads/pdfUpload/WhitePapers/ EvaluatingHospitalPharmacyInventoryManagementandRevenueCyclePr ocesses.pdf. Accessed August 31, 2020.

15. Ackah E, Agboyi MR, Hanson OY. Effectiveness of stock control in the pharmaceutical industry. Dama Int J Res. 2017;1(1):121-130.

16. Mohamed AM, Mohamed IMI, Subish P, Asrul A. Shafie. Medicine expenditures in Sudan national health insurance fund: an ABC-VEN analysis of 5-year medicine consumption. J Pharm Health Serv Res. 2016;7(3):165-171. doi:10.1111/jphs.12136.
17. Emelia DA, Meshach AG, Irene A, Prince AD. An assessment of health commodities management practices in health care delivery; a supply chain perspective. The case of selected hospitals in Ashanti region-Ghana. Eur J Bus Soc Sci. 2014;3(8):78-103.

18. John F. Pareto principle; the 80-20 rule, your guide management. Available from: http://www.wetherhaven.com/ conversation/docu ments/vitalfew2.pdf.

19. Management science for health. MDS 3: Managing Access to Medicine and Health Technologies. Management Support System; Analyzing and Controlling Pharmaceutical Expenditure. Arlington VA; 2012.

20. Misra RB, Ravinder H. ABC analysis for inventory management: bridging the gap between research and classroom. Am J Bus. 2014;7 (3):57-264.

21. Department of health \& family welfare of Odisha. Draft drug stock out assessment. Odisha technical \& management support team: phase II; 2014. Available from: http://www.nrhmorissa.gov.

22. Mani G, Annadurai K, Danasekaran D, Ramasamy J. Drug inventory control analysis in a primary level health care facility in rural Tamil Nadu, India. Healthline. 2014;5(2):36-40.

23. Kumar S, Chakravarty A. ABC VED analysis of expendable medical stores at a tertiary care hospital. Med J Armed Forces India. 2014;14. doi:10.1016/j.mjafi.2014.07.002.

24. Singam A, Dudhgaonkar S, Mamarde A, Salwe KJ, Khan H. ABCVED analysis of drug store in tertiary care hospital for year 2013-14. Indo Am J Pharm Res. 2016;6:6-11.

25. Migbaru S, Yigeremu M, Woldegerima B, Shibeshi W. ABC-VEN matrix analysis of pharmaceutical inventory management in Tikur Anbessa specialized hospital for the years 2009 to 2013, Addis Ababa, Ethiopia. Indian J Basic Appl Med Res. 2016;5(2):734-743.

26. Sefinew A. Assessment of pharmaceuticals inventory management systems for the years $(2008,2009,2010)$ using ABC-VEN matrix analysis at Addis Ababa University College of Health Sciences Tikur Anbessa (Black Lion) Specialized Hospital. Adv Pharmacoepidemiol Drug Saf. 2013;2(3):137. doi:10.4172/2167-1052.1000137.

27. Federal Negarit Gazeta of the Federal Democratic Republic of Ethiopia. Pharmaceuticals Fund and Supply Agency Establishment Proclamation. Addis Ababa, Ethiopia; 2015.

28. Kivoto P. Drug Consumption Patterns with Clinical and Financial Implications at Kenyatta National Hospital. Nairobi, Kenya: University of Nairobi; 2016.

29. Poorwa W, Pandit PT, Zite AR. ABC and VED analysis of the drug store of a tertiary care teaching hospital. Indian J Basic Appl Med Res. 2013;3(1):126-131.

30. YG̈ĞĠT V. Medical materials inventory control analysis at university hospital in Turkey. Int J Health Sci Res. 2017;7(1):227-231.

31. GünerGören H, Dağdeviren O. An excel-based inventory control system based on ABC and VED analyses for pharmacy: a case study. Galore Int J Health Sci Res. 2017;2(1):11-17.

32. Singh S, Gupta AK, Latika DM. ABC and VED analysis of the pharmacy store of a tertiary care, academic institute of the Northern India to identify the categories of drugs needing strict management control. J Young Pharm. 2015;7(2):76-80. doi:10.5530/jyp.2015.2.4.

33. Saxena R, Gokhale C, Kadam D. ABC-VED analysis of the pharmacy of an urban health center. Int J Multidiscip Res Dev. 2017;4(8):233-236.

34. Devnani M, Gupta AK, Nigah R. ABC and VED analysis of the pharmacy store of a tertiary care teaching, research and referral healthcare institute of India. J Young Pharm. 2010;2(2):201-205. doi:10.4103/0975-1483.63170.

35. List of Pharmaceuticals for Dessie Referral Hospital. 1st Edition. Dessie, Ethiopia.; 2012.

36. World Health organization. The World Medicines Situation 2011 Medicines Prices, Availability and Affordability. Geneva, Switzerland: World Health organization; 2011.

37. Deed. Defining and Measuring Accessing to Essential Medicines, Vaccines, Health Commodities; Report for WHO-MSH Constitute Meeting. Fernery Voltaire, France;2004:11-13 
38. Fentie M, Fenta A, Moges F, et al. Availability of essential medicines and inventory management practice in primary public health facilities of Gondar town, north West Ethiopia. J PharmaSciTech. 2015;4 (2):54-56.

39. Ewen M, Kaplan W, Gedif T, et al. Prices and availability of locally produced and imported medicines in Ethiopia and Tanzania. J Pharm Policy Pract. 2017;10(1):7. doi:10.1186/s40545-016-0095-1

40. Abiye Z, Tesfaye A, Hawaze S. Barriers to access: availability and affordability of essential drugs in a retail outlet of a public health center in south western Ethiopia. J Appl Pharm Sci. 2013;3(10):101105. doi:10.7324/JAPS.2013.31017.

41. Pirankar SB, Ferreira AM, Vaz FS, Pereira-Antao I, Pinto NR, Perni SG. Application of ABC-VED analysis in the medical stores of a tertiary care hospital. Int J Pharmacol Toxicol. 2014;4(3):175-177.
42. Singh V, Singh H, Singh S. Drug inventory management of a pharmacy store by combined ABC-VED analysis. IJMER. 2015;3(5):1921.

43. Shah AG, Davda BK, Parikh SB, Bala DV. Always better controlvital essential desirable analysis of the drugs used in health centers of Ahmedabad district. Int J Basic Clin Pharmacol. 2015;4(4):749-752. doi:10.18203/2319-2003.ijbcp20150384

44. Kritchanchai D, Meesamut W. Developing inventory management in hospital. Int J Supply Chain Manag. 2015;4(2):1-19.

45. Dhoka CYL. XYZ inventory classification \& challenges. IOSR $J$ Econ Finance. 2013;2(2):23-26. doi:10.9790/5933-0222326

46. Manivel P, Ranganathen R. Prioritized ABC FSN analysis of inventory management in private and hospital pharmacy followed by questionnaire. Int J Pharm. 2016;7(12):104-113.
Integrated Pharmacy Research and Practice

\section{Publish your work in this journal}

Integrated Pharmacy Research and Practice is an international, peerreviewed, open access, online journal, publishing original research, reports, reviews and commentaries on all areas of academic and professional pharmacy practice. This journal aims to represent the academic output of pharmacists and pharmacy practice with particular focus on integrated care. All papers are carefully peer reviewed

\section{Dovepress}

to ensure the highest standards as well as ensuring that we are informing and stimulating pharmaceutical professionals. The manuscript management system is completely online and includes a very quick and fair peer-review system, which is all easy to use. Visit http://www.dovepress.com/testimonials.php to read real quotes from published authors. 